\title{
Predictors of Lymph Node Metastasis and Prognosis in pT1 Colorectal Cancer Patients with Signet-Ring Cell and Mucinous Adenocarcinomas
}

\author{
Bao-Rong Song ${ }^{a}$ Chang-Chun Xiao ${ }^{a}$ Zhao-Kun Wu \\ aDepartment of General Surgery, Shanghai Electric Power Hospital, Shanghai, bDepartment of Surgery, \\ Fudan University Huadong Hospital, Shanghai, China
}

\section{Key Words}

Colorectal cancer $\bullet$ Signet-ring cell carcinoma • Mucinous carcinoma • Treatment $\bullet$ Prognosis

\begin{abstract}
Background/Aims: The local excision of early colorectal cancer is limited by the presence of lymph node metastasis (LNM). Signet-ring cell carcinomas (SRC) and mucinous adenocarcinomas (MAC) are two relatively infrequent histological subtypes. However, little is known about the predictors of LNM and prognosis to support the feasibility of local excision in early-stage SRC and MAC. Methods: The Surveillance Epidemiology and End Results Database were used to identify all patients with pT1 adenocarcinomas, including conventional adenocarcinoma (AC), MAC, and SRC. The prevalence of LNM was assessed, and the long-term survival rate in the above three types of colorectal cancer was calculated. Results: SRC accounted for $0.3 \%$ and MAC accounted for $4.4 \%$ of the entire cohort of colorectal adenocarcinomas. Compared to $A C, M R C$ and SRC were more often located in the proximal colon, and exhibited a higher grade. The incidence of LNM in AC, MAC, and SRC was $10.6 \%, 17.2 \%$, and $33.3 \%$ for colon cancers and $14.8 \%, 25.9 \%$, and $46.2 \%$ for rectal cancers, respectively. In patients with lymph nodes resected no less than 12 , incidence of LNM in AC, MRC, and SRC was $12 \%, 21 \%$, and $44 \%$ for colon tumors and $17 \%, 30 \%$, and $14 \%$ for rectal tumors, respectively. Although, colon patients MAC showed an entirely worse survival rate than $A C$, rectum patients MAC showed a similar prognosis to AC. We found that in patients with rectal tumors, SRC had a worse 3 and 5-year prognosis than AC. However, for colon cancers, the prognosis of SRC was similar to that of AC. Histology was not found to be an independent prognostic factor in multivariate survival analysis. Conclusions: MAC and SRC are two distinct subtypes of colorectal cancer that require special attention despite their relatively rare prevalence. PT1 patients with SRC of the rectum and patients with MAC of the colon have higher incidences of LNM, and with these adverse outcomes, local excision is not recommended. AlthoughMAC of the rectum and SRC of colon have a high rate of LNM, the prognosis of these types are similar to that of AC.




\section{Cellular Physiology Cell Physiol Biochem 2017;41:1753-1765 \\ \begin{tabular}{ll|l} 
and Biochemistry Published onIIne: IVarch 31, 2017 & $\begin{array}{l}\text { (c) 2017 The Author(s). Published by S. Karger AG, Basel } \\
\text { www.karger.com/cpb }\end{array}$
\end{tabular} \\ Song et al.: Predictors of Lymph Node Metastasis and Prognosis in pT1 Colorectal Cancer Patients}

\section{Introduction}

Primary colorectal signet-ring cell and mucinous carcinoma were first described by Laufman in 1951 and Parham in 1923, respectively [1, 2]. SRC and MAC are distinct from the conventional adenocarcinomas defined by the World Health Organization colorectal histology classification in 1979. SRCs are relatively rare, accounting for approximately $0.1-2.4 \%$ of all primary colorectal cancers, and are characterized by predominantly intracytoplasmic mucin deposition that pushes the nucleus eccentrically. In contrast, MACs (approximately 1.6-25.4\%) are composed of an abundant extracellular mucin pool [3, 4]. Although these histological subtypes may represent entities with unique biological behaviors, aggressiveness, and prognosis, in contrast to the TNM staging and grading system, they are currently not included in the clinical classification system or the guidelines for indications of minimally invasive treatment for early colon and rectal cancer, which simply classify SRC and MAC as undifferentiated cancers $[5,6]$. SRC is not a simple form of undifferentiated adenocarcinoma. Many studies have shown that patients with early signet-ring cell gastric cancer have a more favorable prognosis than patients with other undifferentiated adenocarcinomas $[7,8]$. This phenomenon has been explained by the low possibility of LNM, and it might be considered an indication for endoscopic resection for early gastric cancer with SRC. However, there are few data regarding the indications for local excision of early SRC of colorectal cancer. The present retrospective study based on the surveillance, Epidemiology, and End Results (SEER) database aimed at determining the appropriate management for patients with early SRC and MAC colorectal cancer by analyzing the clinicopathological and long-term survival features of SRC and MAC in early-stage colorectal cancer.

\section{Materials and Methods}

Patient selection strategy and tumor characteristics

The study population was obtained from the records of the SEER database (reference number 12224Nov2013), a program of the National Cancer Institute, which covers approximately 28\% of the population of the United States. Cases of colon (C18.0-18.9, C26.0) and rectal cancer (C19.9, C20.9) from 1988 to 2006

Table 1. Corresponding SEER code of the pathological T1 tumor (TNM7 Map)

\begin{tabular}{|c|c|c|}
\hline $\begin{array}{l}\text { SEER extension } \\
\text { code }\end{array}$ & Colon & Rectum \\
\hline \multicolumn{3}{|l|}{ Prior to 2003} \\
\hline 13 & Head of polyp & Head of polyp \\
\hline 14 & Stalk of polyp & Stalk of polyp \\
\hline 15 & Polyp, NOS & Polyp, NOS \\
\hline 16 & Submucosa (superficial invasion) & Submucosa (superficial invasion) \\
\hline 20 & Muscularis propria invaded & Muscularis propria invaded \\
\hline 30 & Localized, NOS/confined to colon, NOS & Localized, NOS/confined to colon, NOS \\
\hline \multicolumn{3}{|l|}{ Since 2004} \\
\hline 130 & Confined to head of polyp, NOS & Confined to head of polyp, NOS \\
\hline 140 & Confined to stalk of polyp, NOS & Confined to stalk of polyp, NOS \\
\hline 150 & Invasive tumor in polyp, NOS & Invasive tumor in polyp, NOS \\
\hline 160 & $\begin{array}{l}\text { Invades submucosa (superficial invasion), including } \\
\text { submucosa in the head or stalk of a polyp }\end{array}$ & $\begin{array}{l}\text { Submucosa (superficial invasion), including submucosa in } \\
\text { the head or stalk of a polyp }\end{array}$ \\
\hline 165 & & $\begin{array}{l}\text { For rectum: Tumor invading submucosa with intraluminal } \\
\text { extension to colon and/or anal canal/anus }\end{array}$ \\
\hline 170 & Stated as T1 with no other information on extension & Stated as T1 with no other information on extension \\
\hline 300 & Localized, NOS;Confined to colon, NOS & $\begin{array}{l}\text { Confined to rectosigmoid junction, NOS; Confined to } \\
\text { rectum, NOS } \\
\text { Localized, NOS }\end{array}$ \\
\hline
\end{tabular}




\section{Cellular Physiology Cell Physiol Biochem 2017;41:1753-1765}

\begin{tabular}{ll|l} 
DOI: 10.1159/000471868 & O 2017 The Author(s). Published by S. Karger AG, Basel \\
www.karger.com/cpb
\end{tabular}

Song et al.: Predictors of Lymph Node Metastasis and Prognosis in pT1 Colorectal Cancer Patients

Table 2. Corresponding SEER code of the radical surgical Resection

\begin{tabular}{|c|c|c|}
\hline $\begin{array}{l}\text { SEER Site } \\
\text { SpecificSurgery } \\
\text { Code }\end{array}$ & Colon & Rectum(includes rectosigmoid) \\
\hline \multicolumn{3}{|l|}{ Prior to 1998} \\
\hline 30 & $\begin{array}{l}\text { Partial or subtotal colectomy, but less than } \\
\text { hemicolectomy }\end{array}$ & $\begin{array}{l}\text { Anterior/posterior resection, wedge or segmental resection, } \\
\text { transsacral rectosigmoidectomy, Hartmann's operation, } \\
\text { partial proctectomy, rectal resection, NOS }\end{array}$ \\
\hline 40 & $\begin{array}{l}\text { Hemicolectomy or greater (but less than total); } \\
\text { right/left colectomy (all of right or left colonand } \\
\text { a portion of transverse) }\end{array}$ & Pull-through resectionWITH sphincter preservation \\
\hline 50 & Total colectomy & Abdominoperineal resection \\
\hline 60 & Colectomy, NOS & $\begin{array}{l}\text { Any of codes 30-50 PLUS partial or total removal of other } \\
\text { organs }\end{array}$ \\
\hline 70 & $\begin{array}{l}\text { Colectomy PLUS partial or total removal of other } \\
\text { organs }\end{array}$ & Pelvic Exenteration (partial or total); \\
\hline \multicolumn{3}{|l|}{ Since 1998} \\
\hline 30 & $\begin{array}{l}\text { Partial colectomy, but less than } \\
\text { hemicolectomy (with } \\
\text { or without permanent colostomy) }\end{array}$ & $\begin{array}{l}\text { Wedge or segmental resection; partial proctectomy; } \\
\text { proctosigmoidectomy, NOS }\end{array}$ \\
\hline 40 & $\begin{array}{l}\text { Hemicolectomy or greater (but less than total); } \\
\text { right or left colectomy }\end{array}$ & $\begin{array}{l}\text { Pull through WITH sphincter preservation (colo-anal } \\
\text { anastomosis) }\end{array}$ \\
\hline 50 & Total colectomy & Total proctectomy \\
\hline 51 & & Total colectomy \\
\hline 60 & Total proctocolectomy & Total proctocolectomy, NOS \\
\hline 70 & $\begin{array}{l}\text { Colectomy or coloproctectomy WITH an en bloc } \\
\text { resection of other organs; pelvic exenteration }\end{array}$ & $\begin{array}{l}\text { Colectomy, Proctectomy or proctocolectomy WITH an en bloc } \\
\text { resection of other organs; pelvicexenteration }\end{array}$ \\
\hline 80 & Colectomy, NOS & Colectomy, NOS; Proctectomy, NOS \\
\hline
\end{tabular}

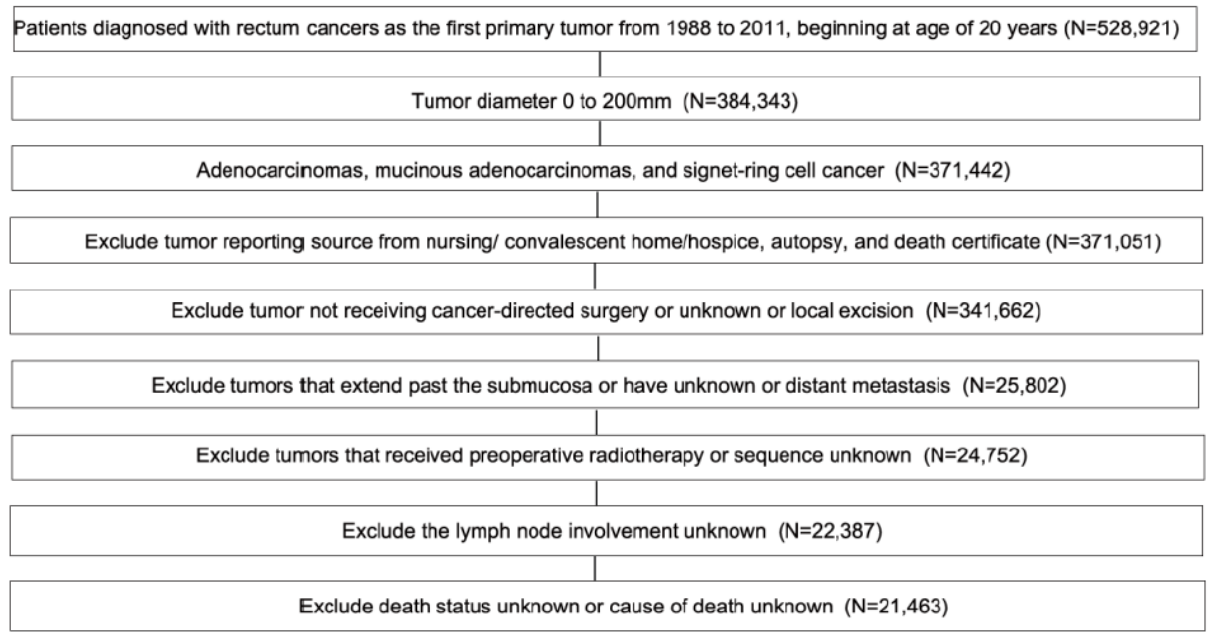

Fig. 1. (A) study flow diagram from the SEER database.

were identified from the SEER database (SEER*Stat 8.1.5) according to the Site Recode Classifications. Only histologically confirmed malignant tumors of colorectal cancer were included, and lesions were confined to the submucosa (T1). The definition of tumor extension in SEER database can be seen in Table 1. We also limited our analysis to patients underwent surgical resection, corresponding detail have been shown in Table 2. Non-first tumors (those involving more than a single primary tumor or in which the primary cancer was not the first of 2 or more primary malignancies), patients treated with preoperative radiation (downstage Tstage), without information of LNs involvement, and with distant metastasis were excluded. For further details, see Fig. 1. Cancer-specific survival was used as the primary outcome parameter. The histological type groups were categorized as follows using the ICD-0-3 (International Classification of Disease for Oncology, 3rd edition), (ICD-10) coding schema: conventional adenocarcinoma (8010, 8020- 
8022, 8140-8141, 8144-8145, 8210-8211, 8220-8221, 8230-8231, 8260-8263), referring to nonmucinous and nonsignet-ring cell tumors; MAC (8470, 8472-8473, 8480-8481); and SRCC (8490) [3, 9]. The "colon" location was defined as cecum, ascending colon, hepatic flexure of the colon, transverse colon, splenic flexure of the colon, descending colon, sigmoid colon, overlapping lesion of the colon, and colon NOS (not otherwise specified). The "rectum" location was defined as the rectosigmoid and rectum [3]. The colon tumors were further divided into three categories: right colon (cecum, ascending colon, and hepatic flexure), transverse colon, and left colon (splenic flexure, descending, and sigmoid colon) tumors. The tumor grades were grouped as follows: Grade I (well differentiated); Grade II (moderately differentiated); Grade III (poorly differentiated); Grade IV (undifferentiated or anaplastic lesions). This study was based on public data from the SEER database, and it did not include interaction with human subjects or the use of personal identifying information. The study was approved by the Review Board of Fudan University Huadong Hospital, Shanghai, China.

\section{Statistical analysis}

Clinicopathological variables in the analysis included age at diagnosis, gender, race, tumor site, therapy (radiation and surgery), tumor size, and tumor grade. Univariate analysis was performed using the Pearson chi-squared method or Fisher's exact test for categorical variables and a Kruskal-Wallis test for continuous variables. The Kaplan-Meier method was employed to calculate the cancer-cause-specific death rate, and the difference between the survival curves was analyzed using a log-rank test. Meanwhile, 3 and 5year survival rates between groups were calculated by log-log transformation for survival function. A Cox proportional hazards model was used in the multivariate analysis [10]. All of the reported tests were 2 -sided, and p values $<0.05$ were considered statistically significant. All statistical analysis was conducted using R statistical software, version 3.1.3, with survival and rms libraries and SPSS version 17.0 for windows (SPSS Inc. Chicago, IL, USA).

\section{Results}

\section{Study cohort}

A total cohort of 21,463 patients matching the inclusion criteria were analyzed in this study, most of whom had AC (95\%). The incidence of SRC was extremely rare and accounted for $0.3 \%$ (62) of all of the patients, whereas that of MAC was $4.4 \%$ (934). The patients' median age was 68 years (range: 20-100 years). The median numbers of resected lymph nodes during the surgery were ten. Lymphadenectomy of 9777 patients (45.5\%) was considered to be adequate (with lymph nodes examined no less than 12). Among the entire cohort, males $(n=11,016)$ were more common than females $(n=10,447)$ and more tumors were located in the colon $(n=15,987,74 \%)$ than in the rectum $(n=5,339,25 \%)$. The race of the population-based study was predominantly white and made up of $81.2 \%$ in AC, $88.4 \%$ in MAC, and 88.7\% in SRC, respectively. For further details, see Table 3.

\section{Clinicopathological characteristics of the patients and the tumors}

SRC were found more frequently to present with younger age compared to AC and MAC, more common in patients younger than 40 years old $(p<0.021$; Table 3$)$, and this comparison was similar in colon patients after stratifying the lesion by tumor location (Table 4). There was a propensity for MAC $(72.6 \%)$ and SRC $(77.1 \%)$ to be located in the proximal colon (large bowel proximal to the splenic flexure) in contrast to AC $(56.5 \%$; $p<$ 0.001). Compared to AC, the percentage of tumor size exceeding $20 \mathrm{~mm}$ of MAC was higher, however, there was a similar distribution with regard to the tumor size between SRC and AC. Colon MAC exhibited a female predominance and rectal SRC cancers was more frequently diagnosed in male (Table 4), compared with the AC group. In terms of tumor differentiation grade, the SRC patients (80.7\%) were diagnosed with high-grade tumors (Grades III and IV) more frequently than the MAC $(10.5 \%)$ and $\mathrm{AC}(7.5 \%$; $<<0.001)$ patients. 


\section{Cellular Physiology Cell Physiol Biochem 2017;41:1753-1765

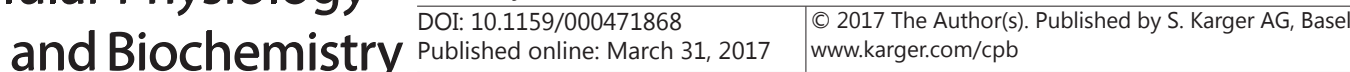 \\ Song et al.: Predictors of Lymph Node Metastasis and Prognosis in pT1 Colorectal Cancer Patients}

Table 3. Characteristics of the SEER database T1 CRC patients by histological type $(\mathrm{n}=21,463)$

\begin{tabular}{|c|c|c|c|c|c|}
\hline Factor & $\begin{array}{l}\text { AC } \\
n=20,467(100 \%)\end{array}$ & $\begin{array}{l}\text { MAC } \\
n=934(100 \%)\end{array}$ & $\mathrm{p}(\mathrm{MAC} v s . \mathrm{AC})$ & $\begin{array}{l}\text { SRC } \\
n=62(100 \%)\end{array}$ & $\mathrm{p}(\mathrm{SRC} v s . \mathrm{AC})$ \\
\hline Age (yr) & & & 0.001 & & 0.021 \\
\hline $20-39$ & $330(1.6)$ & $13(1.4)$ & & $3(4.8)$ & \\
\hline $40-59$ & $5267(25.7)$ & $208(22.2)$ & & $16(25.8)$ & \\
\hline $60-79$ & $11624(56.8)$ & $522(55.9)$ & & $27(43.5)$ & \\
\hline $80+$ & $3246(15.9)$ & $191(20.4)$ & & $16(25.8)$ & \\
\hline \multicolumn{6}{|l|}{ Gender } \\
\hline Male & $10544(51.5)$ & $436(46.7)$ & 0.003 & $36(58.1)$ & 0.303 \\
\hline Female & $9923(48.5)$ & $498(53.3)$ & & $26(41.9)$ & \\
\hline \multicolumn{6}{|l|}{ Race } \\
\hline White & $16612(81.2)$ & $788(84.4)$ & 0.009 & $55(88.7)$ & 0.512 \\
\hline Black & $2105(10.3)$ & $93(10.0)$ & & $3(4.8)$ & \\
\hline Others* & $1658(8.1)$ & $49(5.2)$ & & $4(6.5)$ & \\
\hline Unknown & $92(0.4)$ & $4(0.4)$ & & $0(0)$ & \\
\hline Primarysite & & & $<0.001$ & & $<0.001$ \\
\hline Right colon & $7200(35.2)$ & $501(53.6)$ & & $31(50.0)$ & \\
\hline Transversecolon & $1216(5.9)$ & $70(7.5)$ & & $6(9.7)$ & \\
\hline Left colon & $6737(32.9)$ & $215(23.0)$ & & $11(17.7)$ & \\
\hline Rectum & $5183(25.3)$ & $143(15.3)$ & & $13(21.0)$ & \\
\hline Unknown & $131(0.6)$ & $5(0.5)$ & & $1(1.6)$ & \\
\hline Tumorsize $(\mathrm{mm})$ & & & $<0.001$ & & 0.931 \\
\hline $0-20$ & $12233(59.8)$ & $460(49.3)$ & & $38(61.3)$ & \\
\hline $21-30$ & $4145(20.2)$ & $195(20.9)$ & & $12(19.4)$ & \\
\hline $31-40$ & $1942(9.5)$ & $108(11.5)$ & & $6(9.7)$ & \\
\hline $41-50$ & $1040(5.1)$ & $73(7.8)$ & & $2(3.2)$ & \\
\hline $51-60$ & $502(2.4)$ & $29(3.1)$ & & $2(3.2)$ & \\
\hline $61-80$ & $404(2.0)$ & $37(4.0)$ & & $1(1.6)$ & \\
\hline $80+$ & $201(1.0)$ & $32(3.4)$ & & $1(1.6)$ & \\
\hline Grade & & & $<0.001$ & & $<0.001$ \\
\hline I & $4152(20.3)$ & $189(20.2)$ & & $2(3.2)$ & \\
\hline II & $13514(66.0)$ & $537(57.5)$ & & $6(9.7)$ & \\
\hline III & $1445(7.1)$ & $94(10.1)$ & & $44(71.0)$ & \\
\hline IV & $89(0.4)$ & $4(0.4)$ & & $6(9.7)$ & \\
\hline Unknown & $1267(6.2)$ & $110(11.8)$ & & $4(6.4)$ & \\
\hline No. of LNsdissected & & & 0.968 & & 0.085 \\
\hline$<12$ & $11151(54.5)$ & $508(54.4)$ & & $27(43.5)$ & \\
\hline$\geq 12$ & $9316(45.5)$ & $426(45.6)$ & & $35(56.5)$ & \\
\hline Nstage & & & $<0.001$ & & $<0.001$ \\
\hline No & $18088(88.4)$ & $762(81.6)$ & & $40(64.5)$ & \\
\hline N1 & $2112(10.3)$ & $138(14.8)$ & & $19(30.7)$ & \\
\hline $\mathrm{N} 2$ & $267(1.3)$ & $34(3.6)$ & & $3(4.8)$ & \\
\hline
\end{tabular}

Risk factors for lymph node metastasis

Univariate analysis of risk factors for lymph node metastasis (LNM) found age, grade, tumor size and histological type to be significant factors regardless of tumor location (Table 5). Overall, the rate of LNM was $12.0 \%$ (2,573 out of 21,463). Among these 2,573 patients, $2,379(92.5 \%)$ patients had AC, 22 patients $(0.8 \%)$ had SRC and 172 patients $(6.7 \%)$ had MAC. SRC had a higher rate of LNM (35.5\%) than MAC (18.4\%) and AC (11.6\%). When patients were stratified by site, a similar phenomenon was also seen. In the colon, SRC had an LNM rate of $33.3 \%$, MAC had a rate of $17.2 \%$, and AC had a rate of $10.6 \%$. In the rectum, SRC had an LNM rate of $46.2 \%$, MAC had a rate of $25.9 \%$, and AC had a rate of $14.8 \%$ (Table 6). The multivariate analysis revealed that the age, race, tumor size, location, histological type, and grade were independent factors predicting LNM (Table 7). When patients were stratified by site, similar results were found in the colon patients. However, race was not an independent factor in the patients with rectal tumors (data not shown). 
Table 4. Tumor site-specific demographics

\begin{tabular}{|c|c|c|c|c|c|c|}
\hline \multirow{3}{*}{ Characteristic } & \multicolumn{6}{|c|}{ Tumor site } \\
\hline & \multicolumn{3}{|c|}{ Colon } & \multicolumn{3}{|c|}{ Rectum } \\
\hline & $\begin{array}{l}\text { Adeno carcinoma } \\
(n=15,153)\end{array}$ & $\begin{array}{l}\text { Mucinous } \\
(\mathrm{n}=786)\end{array}$ & $\begin{array}{l}\text { Signet ring } \\
(\mathrm{n}=48)\end{array}$ & $\begin{array}{l}\text { Adenocarcinoma } \\
(\mathrm{n}=5,183)\end{array}$ & $\begin{array}{l}\text { Mucinous } \\
(n=143)\end{array}$ & $\begin{array}{l}\text { Signet ring } \\
(n=13)\end{array}$ \\
\hline \multicolumn{7}{|l|}{ Age(yr) } \\
\hline $20-39$ & $197(1.3)$ & $8(1.0)$ & $3(6.3)$ & $132(2.5)$ & $5(3.5)$ & $0(0)$ \\
\hline $40-59$ & $3544(23.4)$ & $162(20.6)$ & $12(25.0)$ & $1698(32.8)$ & $44(30.8)$ & $4(30.8)$ \\
\hline $60-79$ & $8760(57.8)$ & $440(56.0)$ & $21(43.7)$ & $2784(53.7)$ & $81(56.6)$ & $6(46.2)$ \\
\hline $80+$ & $2652(17.5)$ & $176(22.4)$ & $12(25)$ & $569(11.0)$ & $13(9.1)$ & $3(23.0)$ \\
\hline \multicolumn{7}{|l|}{ Gender } \\
\hline Male & $7636(50.4)$ & $351(44.7)$ & $25(52.1)$ & $2841(54.8)$ & $82(57.7)$ & $11(84.6)$ \\
\hline Female & $7517(49.6)$ & $435(55.3)$ & $23(47.9)$ & $2342(45.2)$ & $61(42.3)$ & $2(15.4)$ \\
\hline \multicolumn{7}{|l|}{ Race } \\
\hline White & $12175(80.3)$ & $665(84.6)$ & $44(91.7)$ & $4324(83.4)$ & $120(83.9)$ & $10(76.9)$ \\
\hline Black & $1758(11.6)$ & $75(9.5)$ & $3(6.3)$ & $334(6.4)$ & $16(11.2)$ & $0(0)$ \\
\hline Others & $1149(7.6)$ & $42(5.3)$ & $1(2.0)$ & $504(7.8)$ & $7(4.9)$ & $3(23.1)$ \\
\hline Unknown & $71(0.5)$ & $4(0.5)$ & $0(0)$ & $21(0.4)$ & $0(0.2)$ & $0(0)$ \\
\hline \multicolumn{7}{|l|}{ Tumorlocation } \\
\hline Right & $7200(47.5)$ & $501(63.7)$ & $31(64.6)$ & - & - & - \\
\hline Transverse & $1216(8.0)$ & $70(8.9)$ & $6(12.5)$ & - & - & - \\
\hline Left & $6737(44.5)$ & $215(27.4)$ & $11(22.9)$ & - & - & - \\
\hline \multicolumn{7}{|l|}{ Tumor size } \\
\hline $0-20$ & $9350(61.7)$ & $383(48.7)$ & $31(64.5)$ & $2800(54.0)$ & $73(51.0)$ & $7(53.8)$ \\
\hline $21-30$ & $2844(18.8)$ & $165(21.0)$ & $9(18.8)$ & $1283(24.8)$ & $30(21.0)$ & $3(23.1)$ \\
\hline $31-40$ & $1390(9.2)$ & $93(11.8)$ & $3(6.2)$ & $539(10.4)$ & $15(10.5)$ & $3(23.1)$ \\
\hline $41-50$ & $772(5.1)$ & $62(7.9)$ & $2(4.2)$ & $263(5.1)$ & $11(7.7)$ & $0(0)$ \\
\hline $51-60$ & $358(2.4)$ & $24(3.1)$ & $2(4.2)$ & $140(2.7)$ & $5(3.5)$ & $0(0)$ \\
\hline $61-80$ & $293(1.9)$ & $32(4.1)$ & $0(0)$ & $106(2.0)$ & $5(3.5)$ & $0(0)$ \\
\hline $80+$ & $146(0.9)$ & $27(3.4)$ & $1(2.1)$ & $52(1.0)$ & $4(2.8)$ & $0(0)$ \\
\hline \multicolumn{7}{|l|}{ Grade } \\
\hline I & $3340(22.0)$ & $168(21.4)$ & $2(4.2)$ & $774(14.9)$ & $19(13.3)$ & $0(0)$ \\
\hline II & $9738(64.3)$ & $442(56.2)$ & $3(6.3)$ & $3698(71.3)$ & $93(65.0)$ & $2(15.4)$ \\
\hline III & $1019(6.7)$ & $80(10.2)$ & $34(70.8)$ & $419(8.1)$ & $14(9.8)$ & $10(76.9)$ \\
\hline IV & $61(0.4)$ & $4(0.5)$ & $5(10.4)$ & $27(0.5)$ & $0(0)$ & $1(7.7)$ \\
\hline Unknown & $995(6.6)$ & $92(11.7)$ & $4(8.3)$ & $265(5.1)$ & $17(11.9)$ & $0(0)$ \\
\hline
\end{tabular}

\section{Survival analysis}

Cancer-specific survival (CSS) was calculated and stratified by histological subtypes and tumor location. The median follow-up interval was 60 months (range: 0-287 months). In total, 1,547 (7\%) patients died from colorectal cancer during the follow-up period. The 3 -year CSS rate was $96.0 \%$ for AC (colon: $96.0 \%$; rectum: 95.8\%), 94.3\% for MAC (colon: 94.1\%; rectum: 95.2\%), and 90.1\% for SRC (colon: 92.4\%; rectum: $82.5 \%$ ). The 5-year CSS rate was $93.3 \%$ for AC (colon: $93.8 \%$; rectum: $92.2 \%$ ), $90.7 \%$ for MAC (colon: $90.5 \%$; rectum: $91.6 \%$ ), and $85.6 \%$ for SRC (colon: $89.2 \%$; rectum: $73.3 \%$ ) (Table 8). For all patients MAC showed an entirely worse survival rate than AC (Fig. 2A). For colon patients, MAC also showed an entirely worse survival rate than AC (Fig. 2B). However, for rectum patients, MAC showed a similar prognosis to AC (Fig. 2C). Comparison of entire survival curves between SRC and AC failed to pick up significant differences. Low incidence of SRC could attribute to the intersection of two curves, which caused the log-rank testis negative and GrambschTherneau test also demonstrated the proportional hazards assumption of Log-rank test is not available. So, we used cloglog transformation for survival function and focused our interest on the comparison at fixed point in time. Adjusted for tumor location, we found that in patients 
with rectal tumors, SRC had a worse 3 and 5-year prognosis than AC. However, for colon cancers, the prognosis of SRC was similar to that of AC $(\mathrm{p}=0.218$ for 3 year; $p=0.204$ for 5 year, Table 8). Adjusted for histology, we found that patients with $\mathrm{AC}$, tumors located in rectum had a worse 5-year prognosis than those located in colon (Fig. 3A). Differently, tumors located in rectum from patients with MAC and SRC had a similar prognosis to tumors located in colon (Fig. 3B and 3C). The patients with MAC, prognosis of these patients in proximal lesion was worse than in distal (Fig. 4).

\section{Multivariate survival analysis}

After adjusting for age, race, tumor size and grade, we performed a multivariate survival analysis stratified by tumor site and histological type was not an independent prognosis factor regardless of tumor site (Table 9). For patients with colon or rectal tumors, African Americans had a higher risk of death compared with whites and other races. High-grade adenocarcinomas, larger tumor size and older patients tended to increase the risk of death in either the colon or the rectum.

\section{Discussion}

Achievement of cure and a better quality of life should both be considered when devising a treatment strategy. Although traditional surgical resection TME (total mesorectal excision) and CME (complete mesocolic excision) achieve excellent oncological control and long-term survival for colorectal cancer patients, these approaches are also associated with substantial morbidity and mortality $[11,12]$.
Table 5. Prevalence of LNM according to histological type and site

\begin{tabular}{lcccccccc}
\hline \multirow{2}{*}{ Histology type } & \multicolumn{2}{c}{ N0 } & \multicolumn{2}{c}{ N1 } & \multicolumn{2}{c}{ N2a } & \multicolumn{2}{c}{ N2b } \\
& No & $\%$ & No & $\%$ & No & $\%$ & No & $\%$ \\
\hline AC & & & & & & & & \\
colon & 13547 & 89.4 & 1443 & 9.5 & 117 & 0.8 & 46 & 0.3 \\
rectum & 4418 & 85.2 & 663 & 12.8 & 71 & 1.4 & 31 & 0.6 \\
unknown & 123 & & 6 & & 2 & & 0 & \\
MAC & & & & & & & & \\
colon(total) & 651 & 82.8 & 111 & 14.1 & 14 & 1.8 & 10 & 1.3 \\
right & 409 & 81.6 & 73 & 14.6 & 11 & 2.2 & 8 & 1.6 \\
transverse & 60 & 85.7 & 7 & 10.0 & 2 & 2.9 & 1 & 1.4 \\
left & 182 & 84.7 & 31 & 14.4 & 1 & 0.5 & 1 & 0.5 \\
rectum & 106 & 74.1 & 27 & 18.9 & 8 & 5.6 & 2 & 1.4 \\
unknown & 5 & & 0 & & 0 & & 0 & \\
SRC & & & & & & & & \\
colon & 32 & 66.7 & 14 & 29.2 & 1 & 2.1 & 1 & 2.1 \\
rectum & 7 & 53.8 & 5 & 38.5 & 1 & 7.7 & 0 & 0 \\
unknown & 1 & & 0 & & 0 & & 0 & \\
\hline
\end{tabular}

Table 6. Tumor site-specific clinical variables correlated with LNM in T1colorectal cancer

\begin{tabular}{|c|c|c|c|c|c|c|}
\hline \multirow{3}{*}{ Characteristic } & \multicolumn{6}{|c|}{ Lymph node metastasis } \\
\hline & \multicolumn{3}{|c|}{ Colon } & \multicolumn{3}{|c|}{ Rectum } \\
\hline & $\begin{array}{l}\text { Positive } \\
(n=1,757)\end{array}$ & $\begin{array}{l}\text { Negative } \\
(n=14,230)\end{array}$ & $p$-value & $\begin{array}{l}\text { Positive } \\
(\mathrm{n}=808)\end{array}$ & $\begin{array}{l}\text { Negative } \\
(\mathrm{n}=4,531)\end{array}$ & p-value \\
\hline Age(yr) & & & $<0.001$ & & & $<0.001$ \\
\hline $20-39$ & $38(18.3)$ & $170(81.7)$ & & $35(25.5)$ & $102(74.5)$ & \\
\hline $40-59$ & $524(14.1)$ & $3194(85.9)$ & & $306(17.5)$ & $1440(82.5)$ & \\
\hline $60-79$ & $956(10.4)$ & $8265(89.6)$ & & $407(14.2)$ & $2464(85.8)$ & \\
\hline $80+$ & $239(8.4)$ & $2601(91.6)$ & & $60(10.3)$ & $525(89.7)$ & \\
\hline Gender & & & 0.122 & & & 0.317 \\
\hline Male & $850(10.6)$ & $7162(89.4)$ & & $377(15.7)$ & $2028(84.3)$ & \\
\hline Female & $907(11.4)$ & $7068(88.6)$ & & $431(14.7)$ & $2503(85.3)$ & \\
\hline Race & & & $<0.001$ & & & 0.3506 \\
\hline White & $1329(10.3)$ & $11555(89.7)$ & & $662(14.9)$ & $3792(85.1)$ & \\
\hline Black & $253(13.8)$ & $1583(86.2)$ & & $61(17.4)$ & $289(82.6)$ & \\
\hline Others & $167(14.0)$ & $1025(86.0)$ & & $83(16.1)$ & $431(83.9)$ & \\
\hline Unknown & $8(10.7)$ & $67(89.3)$ & & $2(9.5)$ & $19(90.5)$ & \\
\hline Histology & & & $<0.001$ & & & $<0.001$ \\
\hline $\mathrm{AC}$ & $1606(10.6)$ & $13547(89.4)$ & & $765(14.8)$ & $4418(85.2)$ & \\
\hline MAC & $135(17.2)$ & $651(82.8)$ & & $37(25.9)$ & $106(74.1)$ & \\
\hline SRC & $16(33.3)$ & $32(66.7)$ & & $6(46.2)$ & $7(53.8)$ & \\
\hline \multicolumn{7}{|l|}{ Tumor location } \\
\hline Right & $765(9.9)$ & $6967(90.1)$ & & - & - & \\
\hline Transverse & $120(9.3)$ & $1172(90.7)$ & & - & - & \\
\hline Left & $872(12.5)$ & $6091(87.5)$ & & - & - & \\
\hline Tumor size $(\mathrm{mm})$ & & & $<0.001$ & & & 0.050 \\
\hline $0-20$ & $975(10.0)$ & $8789(90.0)$ & & $397(13.8)$ & $2483(86.2)$ & \\
\hline $21-30$ & $319(10.6)$ & $2699(89.4)$ & & $216(16.4)$ & $1100(83.6)$ & \\
\hline $31-40$ & 191(12.9) & $1295(87.1)$ & & $87(15.6)$ & $470(84.4)$ & \\
\hline $41-50$ & $127(15.2)$ & $709(84.8)$ & & $56(20.4)$ & $218(79.6)$ & \\
\hline $51-60$ & $62(16.1)$ & $322(83.9)$ & & $23(15.9)$ & $122(84.1]$ & \\
\hline $61-80$ & $57(17.5)$ & $268(82.5)$ & & $19(17.1)$ & $92(82.9)$ & \\
\hline $80+$ & $26(14.9)$ & $148(85.1)$ & & $10(17.9)$ & $46(82.1)$ & \\
\hline Grade & & & $<0.001$ & & & $<0.001$ \\
\hline I & $224(6.4)$ & $3286(93.6)$ & & $72(9.1)$ & $721(90.9)$ & \\
\hline II & $1152(11.3)$ & $9031(88.7)$ & & $567(14.9)$ & $3266(85.1)$ & \\
\hline III & $289(25.5)$ & $844(74.5)$ & & $130(29.3)$ & $313(70.7)$ & \\
\hline IV & $18(25.7)$ & $52(74.3)$ & & $5(17.9)$ & $23(82.1)$ & \\
\hline Unknown & $74(6.8)$ & $1017(93.2)$ & & $34(12.1)$ & $248(87.9)$ & \\
\hline
\end{tabular}


Table 7. Logistic regression analysis of the risk factors for LNM in T1 colorectal cancer

\begin{tabular}{lcccc}
\hline & P-value & Odds ratio & \multicolumn{2}{c}{$95 \%$ confidenceinterval } \\
& & & Lower & Upper \\
\hline Age (ref.=<45 years) & & & & \\
45-65 years & $<0.001$ & 0.71 & 0.59 & 0.86 \\
$>65$ years & $<0.001$ & 0.50 & 0.42 & 0.61 \\
Race(ref.=Black) & & & & \\
Other & 0.930 & 1.01 & 0.84 & 1.21 \\
Unknown & 0.233 & 0.66 & 0.33 & 1.26 \\
White & $<0.001$ & 0.76 & 0.66 & 0.86 \\
Location(ref.=Colon) & & & & \\
Rectum & $<0.001$ & 1.36 & 1.24 & 1.50 \\
Unknown & 0.08 & 0.52 & 0.26 & 1.08 \\
Histology (ref.=AC) & & & & \\
MAC & $<0.001$ & 1.78 & 1.50 & 2.12 \\
SRC & 0.01 & 2.06 & 1.19 & 3.56 \\
Tumor size(ref.>20 mm) & & & & \\
0-20 mm & $<0.001$ & 0.77 & 0.71 & 0.84 \\
Grade (ref.=I-II) & & & & \\
III-IV & $<0.001$ & 2.80 & 2.48 & 3.16 \\
Unknown & $<0.001$ & 0.67 & 0.54 & 0.82 \\
\hline & & & &
\end{tabular}

Table 8. Cause-specific long-term survival rate according to histological subtypes

\begin{tabular}{|c|c|c|c|c|c|c|c|c|c|c|c|c|}
\hline & \multicolumn{6}{|c|}{ Cause-Specific Survival } & \multicolumn{6}{|c|}{$P$ value } \\
\hline & $\mathrm{AC}$ & & MAC & & SRC & & & 3-year & & & 5-year & \\
\hline & 3 year & 5 year & 3 year & 5 year & 3 year & 5 year & MAC vs. AC & MAC vs. SRC & $\begin{array}{c}\text { SRC } s . \\
\text { AC }\end{array}$ & $\begin{array}{c}\text { MAC vs. } \\
\text { AC }\end{array}$ & MAC vs. SRC & $\begin{array}{c}\text { SRC } \\
\text { vs. AC }\end{array}$ \\
\hline All & 0.960 & 0.933 & 0.943 & 0.907 & 0.901 & 0.856 & 0.013 & 0.177 & 0.023 & 0.002 & 0.177 & 0.013 \\
\hline Colon & 0.960 & 0.938 & 0.941 & 0.905 & 0.924 & 0.892 & 0.008 & 0.225 & 0.218 & $<0.001$ & 0.078 & 0.204 \\
\hline Rectum & 0.958 & 0.922 & 0.952 & 0.916 & 0.825 & 0.733 & 0.741 & 0.051 & 0.011 & 0.075 & 0.015 & 0.002 \\
\hline
\end{tabular}

Particularly for distal rectal cancer patients, permanent colostomy is distressing and some patients develop inferiority or depression.

The management of early-stage colorectal cancer remains controversial and lacks sufficient evidence to guide decision making. Although local excision, as an alternative to TME and CME, shows advantages in terms of preserving anal function, fewer complications and shorter hospital stays compared with the curative procedure, it is inferior to radical resection for oncological outcomes and does not adequately remove the regional lymph nodes. Previous studies reported that LNM occurs in $6.3 \%$ to $17 \%$ of T1 and $10 \%$ to $22 \%$ of T2 colorectal cancers $[13,14]$. Our analysis, based on population data, demonstrated that the rate of lymph node metastasis of T1 colorectal cancers was $12.0 \%$. The risk of LNM in patients with colon cancers is $11.0 \%$, with a similar rate for patients with rectal cancer (15.1\%), which was consistent with previous reports [15-17]. Identifying a subgroup of patients for whom local excision would be safe is crucial when planning a tailored strategy. The National Comprehensive Cancer Network describes malignant lesions with T1, Grades I or II, no angiolymphatic invasion, and negative margin of resection as safe for endoscopic removal. However, the guidelines do not mention the histology subtypes. The JSCCR Guideline (Japanese Society for Cancer of the Colon and Rectum) simply classifies mucinous adenocarcinoma and signet-ring cell carcinoma into the poorly differentiated group [18].

Because of the rare occurrence of SRC and MAC, the clinical evaluation of these cancer types is difficult, in particular at the early stage. The SEER database provides a sufficiently KARGER 
Fig. 2. Cancer-specific survival (CSS) was calculated and stratified by histological subtypes. (A) CSS for patients with cancer of all locations, stratified by histology of AC (solid black line), MAC (dot red line), and SRC (solid blue line). (B) CSS for patients with cancer of the colon, stratified by AC, MAC and SRC. (C) CSS for patients with cancer of the rectum, stratified by AC, MAC, and SRC.

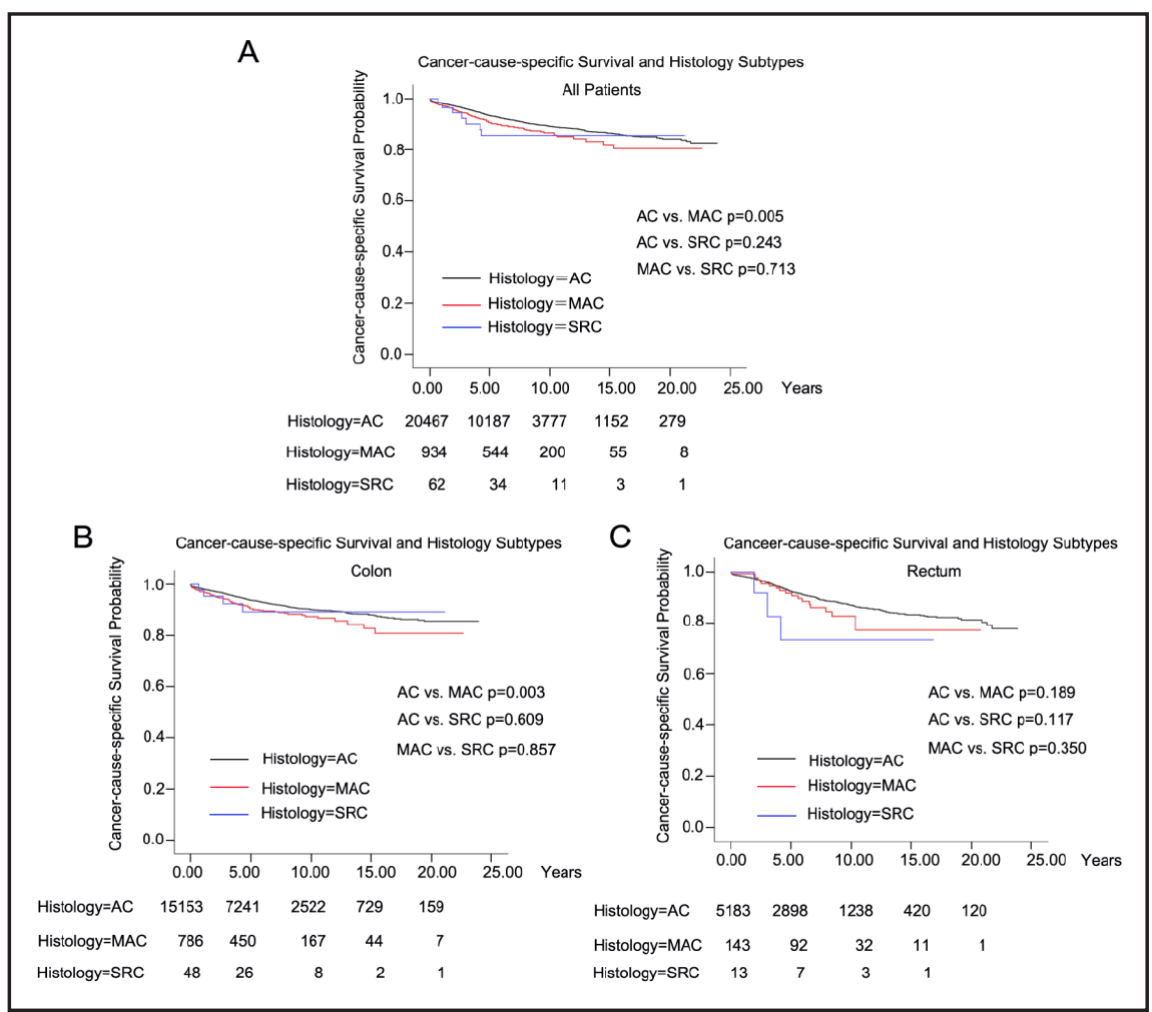

large sample size to conduct such an evaluation. To our knowledge, our study is the only large-cohort study to investigate the possibility of local excision in early-stage colorectal patients with MAC and SRC.

Consistent with a majority of previous large-cohort retrospective analyses from the US, Europe and Asia, MAC and SRC had a propensity to be located in the proximate colon, to present in younger patients, to exhibit a worse differentiated grade and higher likelihood of LNM, and to be found in advanced TNM stages $[5,6,9,19]$. In contrast to these studies, we focused our analysis on patients, whose lesions were confined to the submucosa and aimed to expand the indication for local excision, enabling individually tailored regimens for these patients. Our study will aid in the planning of individually tailored regimens. For example, a subgroup of patients had a chance to preserve their bowel function, reduce their morbidity or mortality rates and lead a better quality of life. With an increasing number of patients having early cancers of the colon and rectum, it is imperative to alter how we assess colorectal cancers. There are many methods for treating colorectal cancer patients, including endoscopic submucosal dissection, transanal endoscopic microsurgery, laparoscopically assisted endoluminal resection, laparoscopic colectomy, and open radical resections, each of which has specific indications. Patients with colorectal cancer should be evaluated by a multidisciplinary team and subjected to the least invasive treatment modality required to obtain cost-effective, patient-friendly cancer remedies.

SRC of colorectal adenocarcinomas share common features of those that are typically expressed in SRC of gastric cancer [19]. However, as opposed to our expectation based on early gastric SRC research, the incidence of LNM in patients with MAC and SRC is high. LNM is associated with $18.4 \%$ of patients with MAC and $35.5 \%$ of patients with SRC, with similar rates when the patients are divided by site (MAC: colon $17.2 \%$, rectum $25.9 \%$; SRC: colon $33.4 \%$, rectum $46.2 \%$ ). Moreover, this result may underestimate the true incidence of LNM because of inadequate lymphadenectomy. Of all of the patients, 54.5\% represented an insufficient number of resected lymph nodes (fewer than 12).When limiting our analysis in patients with adequate lymph node removed, the incidence of LNM was higher. 
Fig. 3. Cancer-specific survival (CSS) was calculated and stratified by histological subtypes. (A) CSS for patients with with AC, stratified by tumor location. (B) CSS for patients with MAC, stratified by tumor location. (C) CSS for patients with SRC, stratified by tumor location.

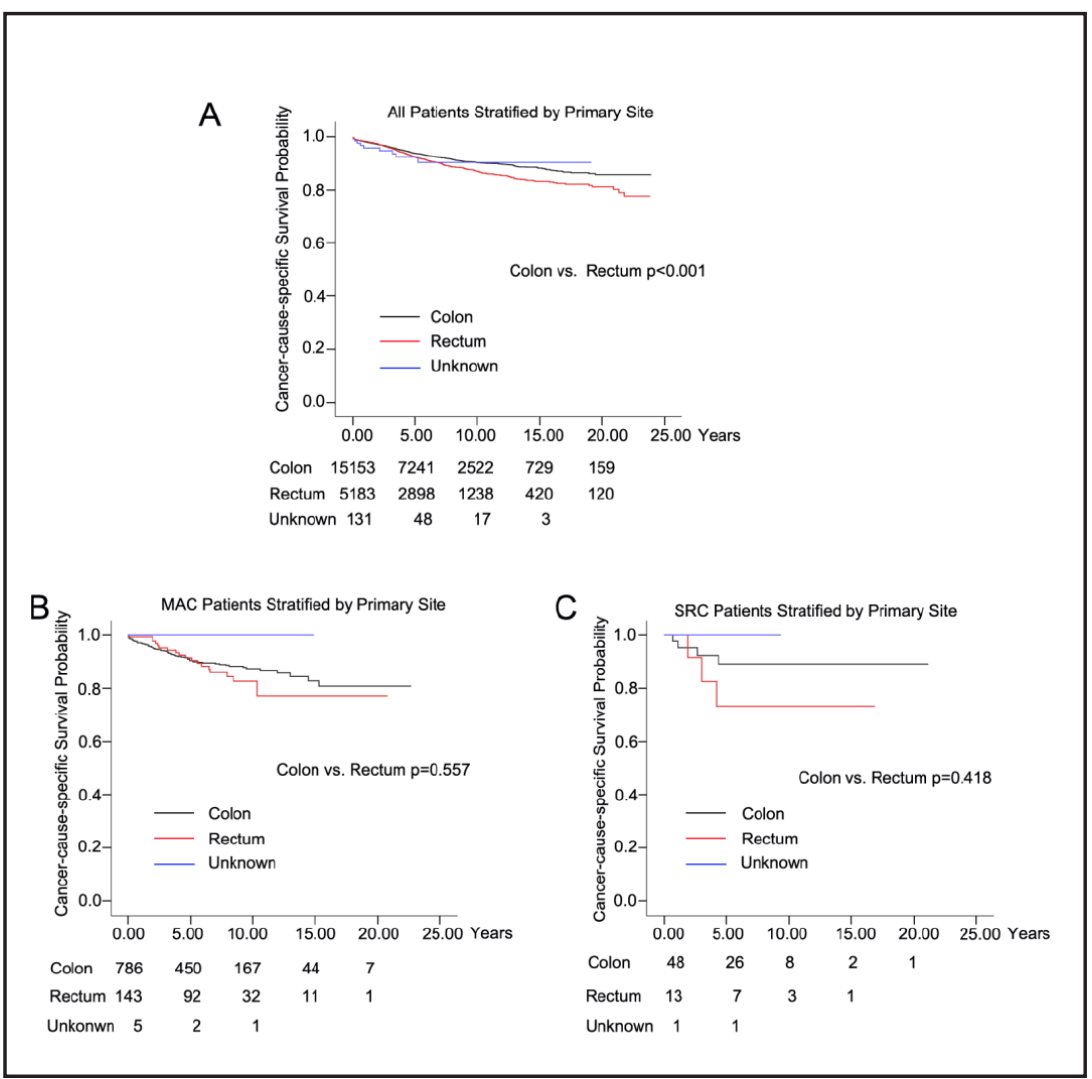

Patients with SRC experienced reduced 3 and 5 survival rates in rectum patients, and the patients with MAC showed reduced 3 and 5 survival rates in colon patients. Rectum patients with MAC and colon patients with SRC showed no difference compared to those with AC. After adjusting for age, race, grade, tumor size, $\mathrm{N}$ stage, therapy regimen and site, a multivariate analysis also did not find histology to be an independent prognostic factor.

The aggressive behavior and reduced survival associated with SRC has been demonstrated by many previous studies, and many researchers attribute this phenomenon to a greater propensity of SRC histology to reach advanced stage, driven by the absence of the expression of adhesive molecules such as E-cadherin and $\beta$-catenin, which causes the tumor cells to have a more aggressive behavior and to disperse to other organs [20,21]. Our research demonstrated high prevalence of LNM of SRC in both colon and rectum tumor, while didn't find the adverse prognosis of SRC in colon cancer.

However, the prognostic implications of MAC remain controversial. It has been reported that MAC was associated with a poorer prognosis, but others did not find that MAC adversely influenced the clinical outcomes [22]. An increasing number of studies have found that the prognostic role for MAC is more dependent on the tumor stage or the specific tumor site $[3$, 9].

\section{KARGER}


Table 9. Independent prognostic factors in the multivariate survival analysis

\begin{tabular}{|c|c|c|c|c|c|c|c|c|}
\hline \multirow[t]{3}{*}{ Variable } & \multicolumn{8}{|c|}{ Tumor Site } \\
\hline & \multicolumn{4}{|c|}{ Colon } & \multicolumn{4}{|c|}{ Rectum } \\
\hline & $P$-value & HR & \multicolumn{2}{|c|}{$95 \% \mathrm{CI}$} & $P$-value & HR & \multicolumn{2}{|c|}{$95 \% \mathrm{CI}$} \\
\hline 45-65years & 0.457 & 0.85 & 1.25 & 1.29 & 0.367 & 1.25 & 0.77 & 2.00 \\
\hline$>65$ years & 0.002 & 1.88 & 0.56 & 2.83 & $<0.001$ & 2.69 & 1.68 & 4.30 \\
\hline \multicolumn{9}{|c|}{ Race(ref.=Black) } \\
\hline Other & $<0.001$ & 0.53 & 0.38 & 0.72 & $<0.001$ & 0.38 & 0.25 & 0.58 \\
\hline White & $<0.001$ & 0.72 & 0.60 & 0.86 & 0.502 & 0.50 & 0.37 & 0.66 \\
\hline Unknown & 0.325 & 0.50 & 0.12 & 2.00 & $<0.001$ & 0.51 & 0.07 & 3.67 \\
\hline \multicolumn{9}{|c|}{ Tumor size(ref.=>20 mm) } \\
\hline $0-20 \mathrm{~mm}$ & $<0.001$ & 0.57 & 0.50 & 0.64 & $<0.001$ & 0.69 & 0.57 & 0.82 \\
\hline \multicolumn{9}{|c|}{ Grade(ref.=I-II) } \\
\hline III-IV & 0.029 & 1.25 & 1.02 & 1.53 & 0.006 & 1.43 & 1.10 & 1.87 \\
\hline Unknown & 0.707 & 0.95 & 0.75 & 1.22 & 0.309 & 0.80 & 0.52 & 1.23 \\
\hline \multicolumn{9}{|c|}{ Adjuvant Radiation (ref.=No) } \\
\hline Yes & 0.008 & 2.10 & 1.21 & 3.66 & $<0.001$ & 1.67 & 1.50 & 1.85 \\
\hline \multicolumn{9}{|c|}{ Nstage(ref.=N0) } \\
\hline N1 & $<0.001$ & 2.52 & 2.16 & 2.95 & $<0.001$ & 2.01 & 1.67 & 2.51 \\
\hline $\mathrm{N} 2$ & $<0.001$ & 4.47 & 3.30 & 6.07 & $<0.001$ & 4.25 & 2.91 & 6.21 \\
\hline \multicolumn{9}{|c|}{ No. of LNs dissected(ref. $=<12)$} \\
\hline$\geq 12$ & $<0.001$ & 0.77 & 0.68 & 0.88 & - & - & - & - \\
\hline
\end{tabular}

Some researchers attribute these discrepancies to geographical variations, patient selection, differences in the defined histological criteria for MAC, and molecular alterations $[19,23]$. Leopoldo et al. and Liu et al. identified two subtypes of mucinous adenocarcinoma of colorectal cancer [23, 24]. The MAC with MSI (microsatellite instability) phenotype presented an earlier TNM stage, a lower frequency of cancer recurrence and better survival compared with conventional adenocarcinoma and MSS (microsatellite stable) mucinous tumors. Compared to MAC in rectal lesions, MAC in colon lesions is associated with a higher MSI, a loss of hMlh1 expression, and a lower or absent p27 expression, and MSI mucinous adenocarcinomas tend to be located in the proximal colon [25-27]. Interestingly, in contrast to previous studies, we analyzed the rate of LNM according to the subdivided colon sites and found the proximal lesion to be associated with a higher incidence of LNM, and prognosis of these patients was worse than in distal.

Several inherent limitations of the SEER database were involved in this study. First, the white race predominated, and the lack of groups such Asians and Hispanics in this study requires that the findings be generalized with caution. Second, the SEER database does not contain information on the adjuvant therapy and the family history, which may be directly related to patients' outcomes. HNPCCs (hereditary nonpolyposis colorectal cancers) have a propensity to exhibit colloid pathology, and compared with the matched stage of sporadic cancer, these specific tumors are associated with improved survival rates [28]. The status of angioinvasion and lymphatic invasion, recurrence and MSI data are also not captured in the SEER database, and therefore, the impact of this information were not included in this study. Third, preoperative radiation may increase the proportion of mucin in primary tumors. The increasing component of mucin reflects the sensitivity to radiotherapy and improves prognosis.

\section{Conclusion}

MAC and SRC are not common forms of adenocarcinomas, especially early-stage colorectal carcinomas. The histological subtypes and differentiated grades should be 
considered separately. Pre- and postoperative routine pathological reports should include information about the histology. Our data suggest that pT1 patients with SRC and patients with MAC of the rectum have a high incidence of LNM, and with these adverse outcomes, local excision is not recommended. Although MAC of the rectum and SRC of the colon have a high rate of LNM, the prognosis of these types is similar to that of AC.

\section{Disclosure Statement}

The authors declare that there is no conflict of interest that could be perceived as prejudicing the impartiality of the reported research.

\section{References}

1 Laufman H, Saphir O: Primary linitis plastica type of carcinoma of the colon. AMA Arch Surg 1951;62:7991.

2 Parham D: Colloid carcinoma. Ann Surg 1923;77:90-105.

3 Kang H, O'Connell JB, Maggard MA, Sack J, Ko CY: A 10-year outcomes evaluation of mucinous and signetring cell carcinoma of the colon and rectum. Dis Colon Rectum 2005;48:1161-1168.

4 Chen JS, Hsieh PS, Chiang JM, Yeh CY, Tsai WS, Tang R, Changchien CR, Wu RC: Clinical outcome of signet ring cell carcinoma and mucinous adenocarcinoma of the colon. Chang Gung Med J 2010;33:51-57.

-5 Chew MH, Yeo SA, Ng ZP, Lim KH, Koh PK, Ng KH, Eu KW: Critical analysis of mucin and signet ring cell as prognostic factors in an asian population of 2,764 sporadic colorectal cancers. Int J Colorectal Dis 2010;25:1221-1229.

6 Nitsche U, Zimmermann A, Spath C, Muller T, Maak M, Schuster T, Slotta-Huspenina J, Kaser SA, Michalski CW, Janssen KP, Friess H, Rosenberg R, Bader FG: Mucinous and signet-ring cell colorectal cancers differ from classical adenocarcinomas in tumor biology and prognosis. Ann Surg 2013;258:775-782,782-783.

7 Ha TK, An JY, Youn HK, Noh JH, Sohn TS, Kim S: Indication for endoscopic mucosal resection in early signet ring cell gastric cancer. Ann Surg Oncol 2008;15:508-513.

8 Kim HM, Pak KH, Chung MJ, Cho JH, Hyung WJ, Noh SH, Kim CB, Lee YC, Song SY, Lee SK: Early gastric cancer of signet ring cell carcinoma is more amenable to endoscopic treatment than is early gastric cancer of poorly differentiated tubular adenocarcinoma in select tumor conditions. Surg Endosc 2011;25:30873093.

-9 Hyngstrom JR, Hu CY, Xing Y, You YN, Feig BW, Skibber JM, Rodriguez-Bigas MA, Cormier JN, Chang GJ: Clinicopathology and outcomes for mucinous and signet ring colorectal adenocarcinoma: analysis from the national cancer data base. Ann Surg Oncol 2012;19:2814-2821.

$\checkmark 10$ Klein JP, Logan B, Harhoff M, Andersen PK: Analyzing survival curves at a fixed point in time. Stat Med 2007;26:4505-4519.

-11 Zhu G, Huang Q, Zheng W, Huang Y, Hua J, Yang S, Zhuang J, Wang J, Chang J, Xu J, Ye J: LPS Upregulated VEGFR-3 Expression Promote Migration and Invasion in Colorectal Cancer via a Mechanism of Increased NF- $\kappa B$ Binding to the Promoter of VEGFR-3. Cell Physiol Biochem 2016;39:1665-1678.

12 Xu K, Liu X, Mao X, Xue L, Wang R, Chen L, Chu X: MicroRNA-149 suppresses colorectal cancer cell migration and invasion by directly targeting forkhead box transcription factor FOXM1. Cell Physiol Biochem 2015;35:499-515.

13 Nash GM, Weiser MR, Guillem JG, Temple LK, Shia J, Gonen M, Wong WD, Paty PB: Long-term survival after transanal excision of $\mathrm{t} 1$ rectal cancer. Dis Colon Rectum 2009;52:577-582.

14 You YN: Local excision: is it an adequate substitute for radical resection in $\mathrm{t} 1 / \mathrm{t} 2$ patients? Semin Radiat Oncol 2011;21:178-184.

15 Stitzenberg KB, Sanoff HK, Penn DC, Meyers MO, Tepper JE: Practice patterns and long-term survival for early-stage rectal cancer. J Clin Oncol 2013;31:4276-4282. 
Song et al.: Predictors of Lymph Node Metastasis and Prognosis in pT1 Colorectal Cancer Patients

16 Saraste D, Gunnarsson U, Janson M: Predicting lymph node metastases in early rectal cancer. Eur J Cancer 2013;49:1104-1108.

17 Althumairi AA, Gearhart SL: Local excision for early rectal cancer: transanal endoscopic microsurgery and beyond. J Gastrointest Oncol 2015;6:296-306.

18 Watanabe T, Itabashi M, Shimada Y, Tanaka S, Ito Y, Ajioka Y, Hamaguchi T, Hyodo I, Igarashi M, Ishida H, Ishihara S, Ishiguro M, Kanemitsu Y, Kokudo N, Muro K, Ochiai A, Oguchi M, Ohkura Y, Saito Y, Sakai Y, Ueno H, Yoshino T, Boku N, Fujimori T, Koinuma N, Morita T, Nishimura G, Sakata Y, Takahashi K, Tsuruta O, Yamaguchi T, Yoshida M, Yamaguchi N, Kotake K, Sugihara K: Japanese society for cancer of the colon and rectum (jsccr) guidelines 2014 for treatment of colorectal cancer. Int J Clin Oncol 2015;20:207-239.

19 Du W, Mah JT, Lee J, Sankila R, Sankaranarayanan R, Chia KS: Incidence and survival of mucinous adenocarcinoma of the colorectum: a population-based study from an asian country. Dis Colon Rectum 2004; 47:78-85.

20 Borger ME, Gosens MJ, Jeuken JW, van Kempen LC, van de Velde CJ, van Krieken JH, Nagtegaal ID: Signet ring cell differentiation in mucinous colorectal carcinoma. J Pathol 2007;212:278-286.

21 Sung CO, Seo JW, Kim KM, Do IG, Kim SW, Park CK: Clinical significance of signet-ring cells in colorectal mucinous adenocarcinoma. Mod Pathol 2008;21:1533-1541.

22 Verhulst J, Ferdinande L, Demetter P, Ceelen W: Mucinous subtype as prognostic factor in colorectal cancer: a systematic review and meta-analysis. J Clin Pathol 2012;65:381-388.

23 Leopoldo S, Lorena B, Cinzia A, Gabriella DC, Angela LB, Renato C, Antonio M, Carlo S, Cristina P, Stefano C, Maurizio T, Luigi R, Cesare B: Two subtypes of mucinous adenocarcinoma of the colorectum: clinicopathological and genetic features. Ann Surg Oncol 2008;15:1429-1439.

24 Liu XP, Sato T, Oga A, Ikemoto K, Kawauchi S, Ikeda E, Sasaki K: Two subtypes of mucinous colorectal carcinoma characterized by laser scanning cytometry and comparative genomic hybridization. Int J Oncol 2004;25:615-621.

25 Lengauer C, Kinzler KW, Vogelstein B: Genetic instability in colorectal cancers. Nature 1997;386:623-627. Haydon AM, Jass JR: Emerging pathways in colorectal-cancer development. Lancet Oncol 2002;3:83-88. Martin L, Assem M, Piard F: Are there several types of colorectal carcinomas? Correlations with genetic data. Eur J Cancer Prev 1999;8:S13-S20.

28 You JF, Hsieh LL, Changchien CR, Chen JS, Chen JR, Chiang JM, Yeh CY, Hsieh PS, Fan CW, Liu CT, Tang R: Inverse effects of mucin on survival of matched hereditary nonpolyposis colorectal cancer and sporadic colorectal cancer patients. Clin Cancer Res 2006;12:4244-4250. 